DOI 10.37882/2500-3682.2021.11.18

\title{
СОПОСТАВИТЕЛЬНОЕ ИССЛЕДОВАНИЕ ТАНЦЕВАЛЬНОЙ КУЛЬТУРЫ ОРОКЕНОВ В КИТАЕ И ЭВЕНКОВ В РОССИИ'
}

\section{COMPARATIVE STUDY OF THE DANCE CULTURE OF THE OROKENS IN CHINA AND THE EVENKS IN RUSSIA}

\section{Zhang Rui}

Summary: The article examines two dance cultures - the Oroken people living in China and the Evenki people living in Russia. It is noted that the dance art of each of these ethnic groups has a rich cultural history. Folk dance reflects the development of the people, their life over the centuries of existence, in particular, the cultural traditions of hunting, fishing, as well as religious beliefs. The study of the dance culture of the peoples of China and Russia requires active cooperation of scientists from the two countries, which will contribute to the preservation of the cultural heritage and the development of small peoples.

Keywords: Oroken, China, Evenki, Russia, folk dance, dance culture, ethnos.

\author{
Чжан Жуй \\ Дочент, Хэйхэский университет (Хэйхэ, КНР) \\ 1171052345@qq.com
}

Аннотация: В статье рассмотрены две танцевальные культуры - народа орокенов, проживающих в Китае, и народа эвенков, проживающих в России. Отмечается, что танцевальное искусство каждого из данных этносов имеет богатую культурную историю. Народный танец отражает развитие народа, его жизнь на протяжении веков существования, в частности, культурные традиции охоты, рыбной ловли, а также религиозные верования. Изучение танцевальной культуры народов Китая и России требует активного сотрудничества учёных двух стран, которое будет способствовать сохранению культурного наследия и развитию малых народов.

Ключевые слова: орокены, Китай, эвенки, Россия, народный танец, танцевальная культура, этнос.

Этнические меньшинства китайских орокенов и русских эвенков имеют свои собственные уникальные стили в танцевальном искусстве, сформировавшиеся в условиях длительного существования этносов. Танец представляет собой богатый и ценный культурный ресурс китайских и русских этнических меньшинств. Сравнительное исследование танцевальной культуры китайского этноса орокен и русского этноса эвенков дает более глубокое понимание быта, обычаев, истории данных народов.

Китайский народ орокены проживает в Китае в основном в автономном районе Внутренняя Монголия и провинции Хэйлунцзян. Орокены - одно из этнических меньшинств с небольшим населением на северо-востоке Китая. Это нация охотников, поэтому их одежда, пища, жилье, транспорт, пение и танцы - все демонстрирует характеристики охотничьей нации. В основном орокены живут в лесах Даксинганских гор и говорят на орокенском языке, который принадлежит к тунгусской ветви алтайской языковой семьи и не имеет письменной формы [5]. В ходе длительного развития охотничьего производства и социальных практик орокены создали богатую и красочную духовную культуру, включающую устную эет лучше

Данная статья является результатом научно-исследовательского проекта 2020 г. Исследование в области философии 1 Социальных наук провинции Хэйлунцзян «Сравнительное исследование трансграничной этнической танцевальной культуры Китая и России». Номер проекта: 20YSC161. 
литературу, музыку, танцы и пластические искусства.

Эвенки являются национальным меньшинством, проживающим в России. Будучи типичными представителями небольшой этнической группы на севере России, эвенки являются коренным народом Российской Федерации. Их традиционные верования - шаманизм и ламаизм, а современное - христианство. Половина эвенков в современной России проживает в Эвенкийском автономном округе, который образован в 1930 году, а в 2007 году был присоединен к Красноярскому краю. Округ раскинулся от реки Оби до Охотского моря и от Северного Ледовитого океана до Сахалина. Эвенки в России когда-то заселяли 70 \% территории Сибири. Традиционные промыслы эвенков - это разведение северных оленей и охота.

И танец китайского этноса орокен, и танец эвенков неотделимы от рыбной ловли, охоты; они отражают историю производства, труда и быта поколений. Многие традиционные формы танца произошли от национальных жертвоприношений, охоты, рыбной ловли и производственной деятельности, ритуалов и т.д. Танцы имитируют передвижение диких животных, демонстрируют подражание танцующих их привычкам. При этом наблюдается явное сходство танцев разных этносов, для объяснения которого необходимо более глубокое изучение истории и культуры народов, отношений между ними. Такой анализ, основанный на культурной интеграции, будет способствовать укреплению единства, дружбы и взаимопомощи между названными этническими меньшинствами. Для этого сравним танцевальную культуру орокенов в Китае и эвенков в России.

Народ орокенов за долгую историю создал свою уникальную и красочную музыку, танцы, народные сказки и другие культурные и художественные формы народного творчества. Большинство этих драгоценных форм искусства отражают благородный характер народа орокенов и его стремление к лучшей жизни.

«Танец» на языке орокенов называется «люригерен». Танцы можно условно разделить на развлекательные, трудовые и ритуальные. Независимо от типа танца, скорость его исполнения варьируется от медленной до быстрой, а заканчивается выступление интенсивным движением. Танцевальные представления орокенов обычно сопровождаются не игрой на музыкальных инструментах, а чтением текста и пением. Основные движения ног в танце - перескакивание, борьба ногами и др. В сопровождающих танец песнях часто звучат слова: «Цзехуэй, цзехуэй», «Эхудеху» и др., а также используются ритмические песенные элементы, такие как «Жехэчжэ» и «Цзяхэцзя». Доминируют в танце движения, имитирующие поведение животных, а в пении - их вой. Например, «Птичий танец» - это масштабный танец, ими- тирующий движения нескольких птиц. Исполнители делятся на две команды, разделенные расстоянием более десяти метров. Локти, запястья и пальцы танцоров волнообразно раскачиваются, указывая, к примеру, на то, что дикий гусь летит. Под крики «Гай Су Гай» две команды встречаются, каждая из них вращается по кругу, а руки танцующих образуют полукруг над головами, что указывает: гуси устремляются в небо. Фраза «Гай Су Гай» звучит оглушительно в тот момент, когда люди, как группа гусей, соединяются [1].

В многовековой истории и общественной жизни эвенков религиозные верования являются очень важной духовной и культурной составляющей, представляя собой продукт охотничьей культуры. Древний традиционный шаманизм проникает в духовную сферу эвенков, его характерными чертами являются концепция поклонения природе, примитивное понимание защиты природы и уникальное знание о небе, солнце, луне и звездах, а также форма поклонения им. Традиция эвенков велит: уважайте природу, продолжайте поклоняться животным, тотемам и предкам. Это отражается в танце, который, строго говоря, не является отдельной художественной системой, потому что полностью интегрирован в жизнь эвенков и проявляется в повседневной жизни, работе и жертвоприношениях. Изучение повседневных обычаев эвенков позволяет условно разделить их танцевальное искусство на две категории: одна - это религиозный танец, который во многом совпадает с исполнением жертвоприношений народом орокен; другой - бытовая форма танца, которая в основном используется в жизни, например, при праздновании охоты и счастливого урожая [10].

В силу исторических причин орокены в Китае и эвенки в России несколько изменили свои танцы в разных этнических ареалах. После основания Нового Китая некоторые этнические группы в нём прошли путь от конца первобытного общества к начальной стадии рабовладельческого устройства общества, минуя несколько социальных форм, и непосредственно вошли в социалистическое общество. При этом у данных этносов, к числу которых относится орокены, осталось множество примитивных культурных памятников. Примерно так же развивался этнос эвенков на территории СССР. Танцевальные формы китайского этноса орокена и российских эвенков являются отражением этого процесса, зафиксированным в танце.

В настоящий момент танцевальное искусство данных народов требует внимательного изучения на фоне китайско-российской культурной интеграции.

Танцевальные ритуалы орокенов в Китае и эвенков в России в основном отражают традиции охоты, собирательства, производства, жизни и жертвоприношений; 
они восхваляют храбрость и национальную самобытность данных этнических групп. Между танцами двух этносов наблюдаются сходство и различия, которые обозначим далее.

Развитие китайского и эвенкийского танца отражало следование этносов природе. Изучая танцы орокенов в Китае и эвенков в России, мы можем увидеть, что танец воссоздаёт многие микрокосмы жизни, показывая труд людей, жертвоприношения и др. Восстановление прошлой жизни этноса, его истории посредством исследования танца помогает глубже понять обычаи, проблемы повседневной жизни и социально-экономического развития двух народов. В древности и в наши дни танцы каждой эпохи отражали культурный фон и идеологию конкретного времени; своими уникальными динамическими характеристиками и структурными формами они транслировали социальную и природную основу каждого пережитого этносом исторического этапа. Следовательно, в процессе изучения танца орокен и танца эвенков необходимо неукоснительно следовать естественным народным обычаям и социальным природным формам, воссоздаваемым на фоне времени, что имеет большое значение для содействия развитию танцевальной культуры в двух странах.

Нетрудно обнаружить много общего между танцевальной культурой орокенов и эвенков в двух странах, и это сходство очевидно, в то время как отличия не так значимы, да и не велики. Например, сходство состоит в заимствовании танцевальных элементов из жизни и формировании на их основе полного набора танцевальных приёмов, в которых движения тела используются для выражения внутреннего мира человека. Танец этнической группы орокенов отличается тем, что его содержание отражает повседневный труд, охоту, религиозные верования, давая людям ощущение простоты; в то время как танцы этнической группы эвенков почти всегда наполнены таинственными религиозными смыслами; их ритуал полон тайны, а содержание выражается довольно неясно. При этом обе танцевальные культуры ориги- нальны.

По причине более раннего начала модернизации в России (в СССР) экономическая жизнь, социальная инфраструктура, культурный и образовательный уровень эвенков были подвергнуты трансформациям, и масштабы урбанизации этнической группы эвенков оказались изначально выше, чем у китайской этнической группы орокенов. Хотя модернизация Китая началась поздно, вследствие реформ и гласности народ орокенов в Китае также быстро превратился из сообщества с традиционным экономическим устройством в группу с современной экономикой, в которой сельское хозяйство является основой жизни. Социально-политический статус этноса, экономические условия его жизни, инфраструктура и урбанизация препятствуют сегодня сохранению культуры танца как орокенами, так и эвенками. Обоим этносам не хватает внимания, инвестиций и поддержки для развития танцевального искусства. В современном мире наблюдается действие двух взаимно направленных тенденций. Это тенденция к интеграции народов и этносов (к их объединению и ассимиляции) и одновременно «тенденция к региональному разделению, к политической и культурной автономии малых и средних этносов» $[2$, c. 30]. Вторая тенденция очень важна для развития каждого этноса на планете, и проявляется она в числе прочего повышением внимания к танцевальной культуре малых народов.

Итак, танцевальная культура орокенов в Китае и эвенков в России в основном сосредоточена на повседневных аспектах жизни, труда и жертвоприношений, представленных танцами. Сравнительное изучение танцевальной культуры китайских орокенов и российских эвенков дает ученым знания об искусстве, характере производства, жизни, традициях и обычаях данных этносов, способствует более полному пониманию традиций и менталитета их представителей. Эвенки в России и не похожие на них, но очень близкие к ним орокены в Китае должны приложить все усилия для защиты собственного культурного наследия.

\section{ЛИТЕРАТУРА}

1. Ван Вэньчжан. Введение в нематериальное культурное наследие. Пекин: Издательство Культуры и Искусства, 2016. 312 с.

2. Крылова М.Н. Введение в языкознание для бакалавров: учебное пособие. Саратов: Вузовское образование, 2014. 275 с.

3. Марфусалова В.П., Егорова М.В. Круговые танцы эвенков // Педагогика искусства. 2020. № 1. С. 127-133.

4. Мохов Е.А. Песенная культура эвенков // Искусство глазами молодых. материалы VIII Междунар. (XII Всерос.) научн. конф. Красноярский: КГИИ, 2016. C. 213-215.

5. Пу Личунь. Исследование образовательной наследственности нематериального культурного наследия этнических меньшинств. Пекин: Издательство Национальностей, 2010. 234 с.

6. Сидорова А.М. Эвенкийский танец в системе ценностей традиционной культуры народов Севера // Молодежный вестник Санкт-Петербургского государственного института культуры. 2016. № 1 (5). С. 37-39.

7. Сунь Ш. Традиционные праздники и кулинарная культура народа орокен, проживающего вдоль реки Амур // Культура и цивилизация. 2021. Т. 11. № 2-1. 


\section{C. $12-18$.}

8. Фу Ч., Ян Го. Изобразительное искусство малых народов, занимающихся лесной охотой в бассейне реки Амур // Культурная жизнь Юга России. 2021. № 2 (81). C. 118-125.

9. Хороших П.П. Метание маута на хорей в структуре инициации в традиционной культуре эвенков // Человек и культура. 2019. № 6. С. 106-113.

10. Чжан Чжунмоу. Исследование нематериального культурного наследия. Пекин: Издательство культуры и искусства, 2010. 156 с.

$$
\text { () Чжан Жуй (1171052345@qq.com). }
$$

Журнал «Современная наука: актуальные проблемы теории и практики»

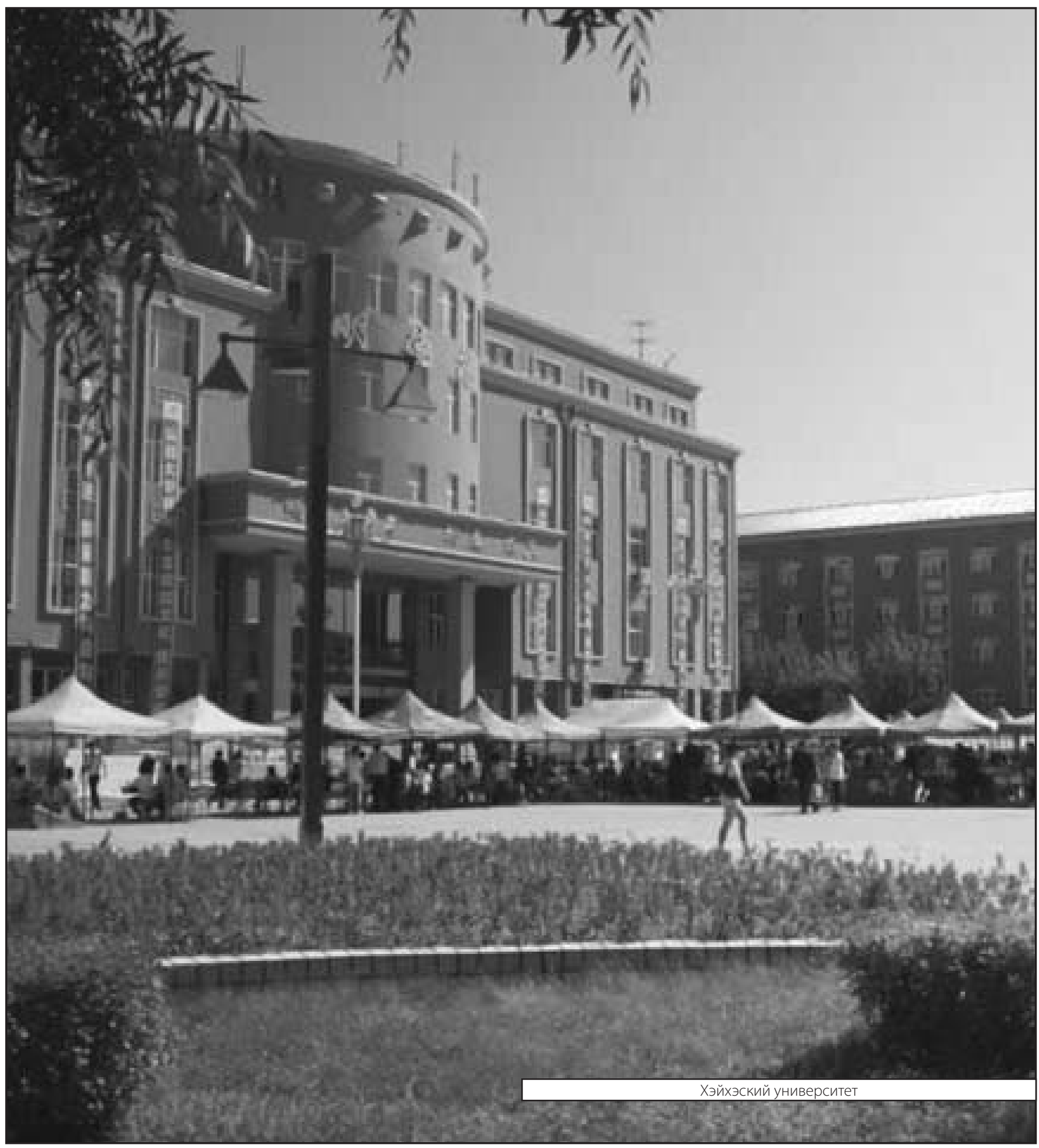

